\title{
Deoxyribonucleic Acid Relatedness Among Selected Strains of Mycobacterium tuberculosis, Mycobacterium bovis, Mycobacterium bovis BCG, Mycobacterium microti, and Mycobacterium africanum
}

\author{
TAMOTSU IMAEDA \\ Department of Microbiology, University of Medicine and Dentistry of New Jersey, New Jersey Medical School, \\ Newark, New Jersey 07103
}

\begin{abstract}
Deoxyribonucleic acids (DNAs) of selected strains of the Mycobacterium tuberculosis complex, including strains of M. tuberculosis, Mycobacterium bovis, M. bovis BCG, Mycobacterium microti, and Mycobacterium africanum, were isolated and analyzed spectrophotometrically. The genome molecular weight and the guanine-plus-cytosine content of the DNA samples were approximately $1.9 \times 10^{9}$ and $62.9 \mathrm{~mol} \%$, respectively. DNA relatedness among the strains was studied by both spectrophometric DNA hybridization and restriction endonuclease cleavage methods. All strains of the four species showed more than $90 \%$ DNA relatedness, except for slightly lower levels ( 85 to $89 \%$ ) of relatedness between $M$. microti and some strains of $M$. bovis, M. bovis BCG, or M. africanum. The distribution patterns of the DNA fragments produced with restriction enzymes, such as $E c o$ RI, $E c o R V, B g I I, B c I I$, and $K p n I$, were indistinguishable upon agarose gel electrophoresis. In contrast, the levels of DNA relatedness between $M$. tuberculosis and other slowly growing mycobacteria, including Mycobacterium nonchromogenicum, Mycobacterium intracellulare, Mycobacterium kansasii, Mycobacterium avium, Mycobacterium scrofulaceum, Mycobacterium haemophilum, Mycobacterium marinum, and Mycobacterium asiaticum, were significantly heterogeneous, ranging from 9 to $53 \%$. My data indicate the extremely close evolutionary relationship among four species of the $M$. tuberculosis complex.
\end{abstract}

Mycobacterium tuberculosis, Mycobacterium bovis, $M$. bovis BCG, Mycobacterium microti, and Mycobacterium africanum are grouped as the $M$. tuberculosis complex based upon their phenetic similarities $(25,26)$. Distinctions among these species are defined on the basis of biochemical $(9,21,25,26)$, bacteriological $(7,13,21,26)$, serological $(8$, $15,19,22)$ and chemical $(23,27)$ properties, their levels of pathogenicity for experimental animals $(10,13,20,21)$, and their levels of susceptibility to some mycobacteriophages $(6$, 28 ). A thorough review of these taxonomic findings has been published by Wayne (26).

However, any of the extensive phenotypic analyses available measure less than $20 \%$ of the total genomic capability of bacteria (4). Consequently, phenotypic differences should not be emphasized as absolute criteria for definition of species. On the other hand, examination of essential properties of chromosomes, such as genome molecular weight, guanine-plus-cytosine content, and deoxyribonucleic acid (DNA) relatedness, provides a more practical and reliable method to determine the genetic relationships among phenetically similar species. In fact, Bradley (3) and Baess (2) reported $100 \%$ DNA homology between $M$. tuberculosis and $M$. bovis, including $M$. bovis BCG strains, showing that these organisms belong to the same species.

In this report I provide additional information concerning the genome molecular weights, base ratios, and extents of DNA relatedness among selected strains of the species of the $M$. tuberculosis complex. A total of $13 M$. bovis BCG strains commonly used for vaccination in the world were also examined to clarify their genetic relatedness within the same species. Furthermore, selected strains of eight established species of slowly growing mycobacteria were analyzed for their DNA relatedness to M. tuberculosis.

\section{MATERIALS AND METHODS}

Bacterial strains and culture conditions. The bacterial strains used in this study and their sources are listed in
Tables 1 and 2. Mycobacterium avium TMC 706 was used in place of the type strain, since this strain has been suggested as the working type by the International Working Group on Mycobacterial Taxonomy (18). All strains were grown in Middlebrook 7H9 medium (Difco Laboratories, Detroit, Mich.) supplemented with either $1 \%$ glucose (for $M$. bovis strains) or $1 \%$ glycerol (for other strains) and $0.25 \%$ bovine serum albumin fraction V (Sigma Chemical Co., St. Louis, Mo.) at $37^{\circ} \mathrm{C}$ with constant shaking at $125 \mathrm{rpm}$, until the optical density at $560 \mathrm{~mm}$ became approximately 1.5 .

Spectrophotometric assay of DNA-DNA hybridization. The methods used for preparation of DNA samples from mycobacteria and determination of melting temperatures for calculation of guanine-plus-cytosine contents and the conditions used for DNA-DNA hybridization for determination of $\mathrm{C}_{0} \mathrm{t}_{0.5}$ values as parameters for estimation of genome molecular weights and levels of DNA relatedness have been described previously $(1,17) ; 100 \%$ homology between samples $\mathrm{A}$ and $\mathrm{B}$ was confirmed by calculating the $\mathrm{C}_{0} \mathrm{t}_{0.5}$ values of mixtures of samples $\mathrm{A}$ and $\mathrm{B}$ at different ratios. If two samples were homologous, the $\mathrm{C}_{0} \mathrm{t}_{0.5}$ values derived from reaction mixtures at different ratios had to be the same.

Restriction endonuclease cleavage analysis. DNA samples of selected strains of mycobacteria were digested with restriction enzymes EcoRI, EcoRV, BglII, Bc/I, and $K p n \mathrm{I}$ (Bethesda Research Laboratories, Bethesda, Md.) according to the instructions of the supplier. The DNA samples were then separated by electrophoresis through agarose gels [1\% in $0.04 \mathrm{M}$ tris(hydroxymethyl)aminomethane acetate buffer containing $0.002 \mathrm{M}$ ethylenediaminetetraacetate, $\mathrm{pH} 8.0$ ], stained with ethidium bromide, and photographed with Polaroid type 55 film.

\section{RESULTS}

Four strains of $M$. tuberculosis, 5 strains of $M$. bovis, 13 strains of $M$. bovis BCG, 2 strains of $M$. microti, and 1 strain of $M$. africanum contained chromosomal DNAs with almost 
identical genome molecular weights and base ratios $(1.9 \times$ $10^{9} \pm 0.1 \times 10^{9}$ and $62.9 \pm 0.3 \mathrm{~mol} \%$, respectively) (Table 1 ). The genome of $M$. bovis BCG TMC 1010 was slightly larger than the other genomes. Among selected strains of slowly growing mycobacteria that did not belong to the $M$. tuberculosis complex, the DNAs of Mycobacterium asiaticum and Mycobacterium kansasii showed characteristics similar to those of $M$. tuberculosis, whereas Mycobacterium nonchromogenicum, Mycobacterium intracellulare, $M$. avium, Mycobacterium scrofulaceum, Mycobacterium haemophilum, and Mycobacterium marinum contained DNAs which differed from the DNA of $M$. tuberculosis with respect to genome molecular weight, base ratio, or both (Table 2).

In the spectrophotometric assay of DNA-DNA hybridization, $M$. tuberculosis showed 9 to 53\% DNA relatedness to $M$. asiaticum, M. marinum, M. haemophilum, $M$. scrofulaceum, $M$. avium, $M$. kansasii, $M$. intracellulare, and $M$. nonchromogenicum, (Table 2).

The extent of DNA relatedness among strains of the $M$. tuberculosis complex was examined by using two strains of each species as references (Table 3 ). M. microti TMC $1619^{\mathrm{T}}$ ( $\mathrm{T}=$ type strain) was not used in this study, because this strain appeared to be heterogeneous even after several single-colony transfers on Middlebrook $7 \mathrm{H} 11$ agar medium. The heterogeneity of the population was evidenced by the

TABLE 1. Origins, genome molecular weights, and base ratios of strains of the $M$. tuberculosis complex

\begin{tabular}{|c|c|c|}
\hline Strain & $\begin{array}{l}\text { Genome } \\
\text { mol wt } \\
\left(10^{9}\right)^{a}\end{array}$ & $\begin{array}{l}\text { Guanine-plus- } \\
\text { cytosine con- } \\
\text { tent (mol\%) }\end{array}$ \\
\hline \multicolumn{3}{|l|}{ M. tuberculosis } \\
\hline $\operatorname{TMC} 102^{\mathrm{T}}\left(=\mathrm{H} 37 \mathrm{Rv}^{\mathrm{T}}\right)^{\mathrm{C}}$ & 2.0 & 63.3 \\
\hline TMC 201 (= H37Ra) & 1.9 & 63.1 \\
\hline TMC 327 & 2.0 & 63.3 \\
\hline MH $1160^{d}$ & 2.0 & 62.7 \\
\hline \multicolumn{3}{|l|}{ M. bovis } \\
\hline ATCC $19210^{\mathrm{Te}}$ & 1.8 & 62.7 \\
\hline TMC 401 (Ravenel) & 1.9 & 62.9 \\
\hline TMC 405 & 1.8 & 63.3 \\
\hline TMC 407 (Branch) & 1.9 & 62.9 \\
\hline TMC 409 (Vallee) & 1.9 & 63.1 \\
\hline \multicolumn{3}{|l|}{ M. bovis $\mathrm{BCG}$} \\
\hline TMC 1010 (Danish) & 2.3 & 62.9 \\
\hline TMC 1011 (Pasteur) & 1.9 & 63.3 \\
\hline TMC 1012 (Montreal) & 1.9 & 62.8 \\
\hline TMC 1013 (Brazilian) & 2.0 & 62.5 \\
\hline TMC 1019 (Japanese) & 1.8 & 62.9 \\
\hline TMC 1020 (Mexican) & 2.0 & 62.9 \\
\hline TMC 1021 (Australian) & 1.9 & 62.9 \\
\hline TMC 1022 (Russian) & 2.0 & 62.9 \\
\hline TMC 1024 (Glaxo) & 1.8 & 62.7 \\
\hline TMC 1025 (Prague) & 1.9 & 62.9 \\
\hline TMC 1028 (Tice) & 2.1 & 62.7 \\
\hline TMC 1029 (Phipps) & 1.8 & 62.9 \\
\hline TMC 1030 (Connaught) & 1.9 & 62.7 \\
\hline M. africanum TMC 5122 & 2.0 & 62.7 \\
\hline \multicolumn{3}{|l|}{ M. microti } \\
\hline TMC 1608 & 1.9 & 62.3 \\
\hline $26003^{f}$ & 1.9 & 63.3 \\
\hline
\end{tabular}

a Average of six assays.

${ }^{b}$ Average of three to six assays.

c TMC, Trudeau Mycobacterial Culture Collection (strains supplied by the National Jewish Hospital through the National Institute of Allergy and Infectious Diseases).

${ }^{d}$ Isolated from a patient with pulmonary tuberculosis in the Unversity of Medicine and Dentistry of New Jersey Hospital, Newark.

'ATCC, American Type Culture Collection, Rockville, Md.

${ }^{f}$ Supplied by M. Tsukamura, National Chubu Hospital, Japan.
TABLE 2. Genome molecular weights, base ratios, and levels of DNA relatedness observed between $M$. tuberculosis and other mycobacterial species

\begin{tabular}{|c|c|c|c|}
\hline Strain & $\begin{array}{c}\text { Genome } \\
\text { mol wt } \\
\left(10^{9}\right)^{a}\end{array}$ & $\begin{array}{l}\text { Guanine-plus- } \\
\text { cytosine con- } \\
\text { tent }(\mathrm{mol} \%)^{b}\end{array}$ & $\begin{array}{c}\% \text { Relatedness } \\
\text { with } M \text {. tuber } \\
\text { culosis TMC } \\
102^{\text {Tc }}\end{array}$ \\
\hline 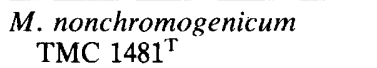 & 1.8 & 64.7 & 53 \\
\hline$M$. intracellulare TMC $1406^{\mathrm{T}}$ & 2.0 & 65.7 & 48 \\
\hline M. kansasii TMC $1204^{\mathrm{T}}$ & 2.2 & 63.3 & 32 \\
\hline$M$. avium TMC 706 & 2.3 & 66.7 & 27 \\
\hline M. scrofulaceum TMC $1323^{\mathrm{T}}$ & 2.4 & 65.8 & 22 \\
\hline M. haemophilum TMC $804^{\mathrm{T}}$ & 1.8 & 61.5 & 17 \\
\hline M. marinum TMC $1218^{\mathrm{T}}$ & 2.5 & 63.1 & 11 \\
\hline M. asiaticum TMC $803^{\mathrm{T}}$ & 2.0 & 63.1 & 9 \\
\hline
\end{tabular}

a Average of six assays.

${ }^{b}$ Average of three to six assays.

${ }^{c}$ Average of six assays.

fact that the DNA sample prepared from this strain showed about $90 \%$ DNA relatedness to both $M$. avium and $M$. tuberculosis, which are distantly related (Table 2). Similarly, $M$. microti TMC 1601 was not included, because of its high level of DNA relatedness with $M$. avium or Mycobacterium lepraemurium, as reported previously (1).

The levels of DNA relatedness between $M$. tuberculosis and other members of the $M$. tuberculosis complex ranged from 90 to $100 \%$ (Table 3). $M$. bovis and $M$. bovis BCG

TABLE 3. Levels of DNA relatedness observed among strains of the $M$. tuberculosis complex

\begin{tabular}{|c|c|c|c|c|c|c|}
\hline \multirow{3}{*}{ Strain } & \multicolumn{6}{|c|}{ \% Relatedness with: ${ }^{a}$} \\
\hline & \multicolumn{2}{|c|}{ M. tuberculosis } & \multirow{2}{*}{$\begin{array}{c}\text { M. bovis } \\
\text { ATCC } \\
19210^{\mathrm{T}}\end{array}$} & \multirow{2}{*}{$\begin{array}{c}\text { M. bovis } \\
\text { BCG } \\
\text { TMC } \\
1011\end{array}$} & \multicolumn{2}{|c|}{ M. microti } \\
\hline & $\begin{array}{l}\text { TMC } \\
102^{\mathrm{T}}\end{array}$ & $\begin{array}{c}\text { TMC } \\
201\end{array}$ & & & $\begin{array}{l}\text { TMC } \\
1608\end{array}$ & 26003 \\
\hline \multicolumn{7}{|l|}{ M. tuberculosis } \\
\hline TMC 102 & $\operatorname{Ref}^{b}$ & 100 & 99 & 98 & 100 & 97 \\
\hline TMC 201 & 100 & Ref & 99 & 100 & 90 & 90 \\
\hline TMC 327 & 100 & 100 & 98 & 94 & $\mathrm{ND}^{c}$ & ND \\
\hline MH 1160 & 100 & 99 & 100 & 97 & 96 & 100 \\
\hline \multicolumn{7}{|l|}{ M. bovis } \\
\hline ATCC 19210 & 99 & 99 & Ref & 100 & 100 & 100 \\
\hline TMC 401 & 97 & 100 & 100 & 100 & 91 & 87 \\
\hline TMC 405 & 98 & 100 & 100 & 100 & 96 & 100 \\
\hline TMC 407 & 100 & 97 & 100 & 100 & 96 & 98 \\
\hline TMC 409 & 100 & 100 & 100 & 95 & 96 & 99 \\
\hline \multicolumn{7}{|l|}{ M. bovis $\mathrm{BCG}$} \\
\hline TMC 1010 & 100 & 96 & 100 & 98 & 100 & 100 \\
\hline TMC 1011 & 98 & 100 & 100 & Ref & 100 & 100 \\
\hline TMC 1012 & 97 & 100 & 97 & 100 & 90 & 89 \\
\hline TMC 1013 & 100 & 100 & ND & 100 & ND & ND \\
\hline TMC 1019 & 100 & 100 & 97 & 100 & 96 & 100 \\
\hline TMC 1020 & 100 & 100 & 100 & 100 & 85 & 89 \\
\hline TMC 1021 & 100 & 98 & 100 & 100 & 97 & 99 \\
\hline TMC 1022 & 100 & 97 & 100 & 96 & 95 & 100 \\
\hline TMC 1024 & 100 & 100 & 100 & 100 & 98 & 100 \\
\hline TMC 1025 & 100 & 100 & 100 & 100 & 100 & 100 \\
\hline TMC 1028 & 98 & 100 & 97 & 100 & ND & ND \\
\hline TMC 1029 & 100 & 99 & 100 & 100 & 100 & 100 \\
\hline TMC 1030 & 100 & 100 & 100 & 100 & 98 & 99 \\
\hline \multicolumn{7}{|l|}{ M. africanum } \\
\hline TMC 5122 & 100 & 100 & 96 & 95 & 98 & 89 \\
\hline
\end{tabular}

a Average of six assays.

${ }^{b}$ Ref, Reference.

${ }^{c}$ ND, Not done. 


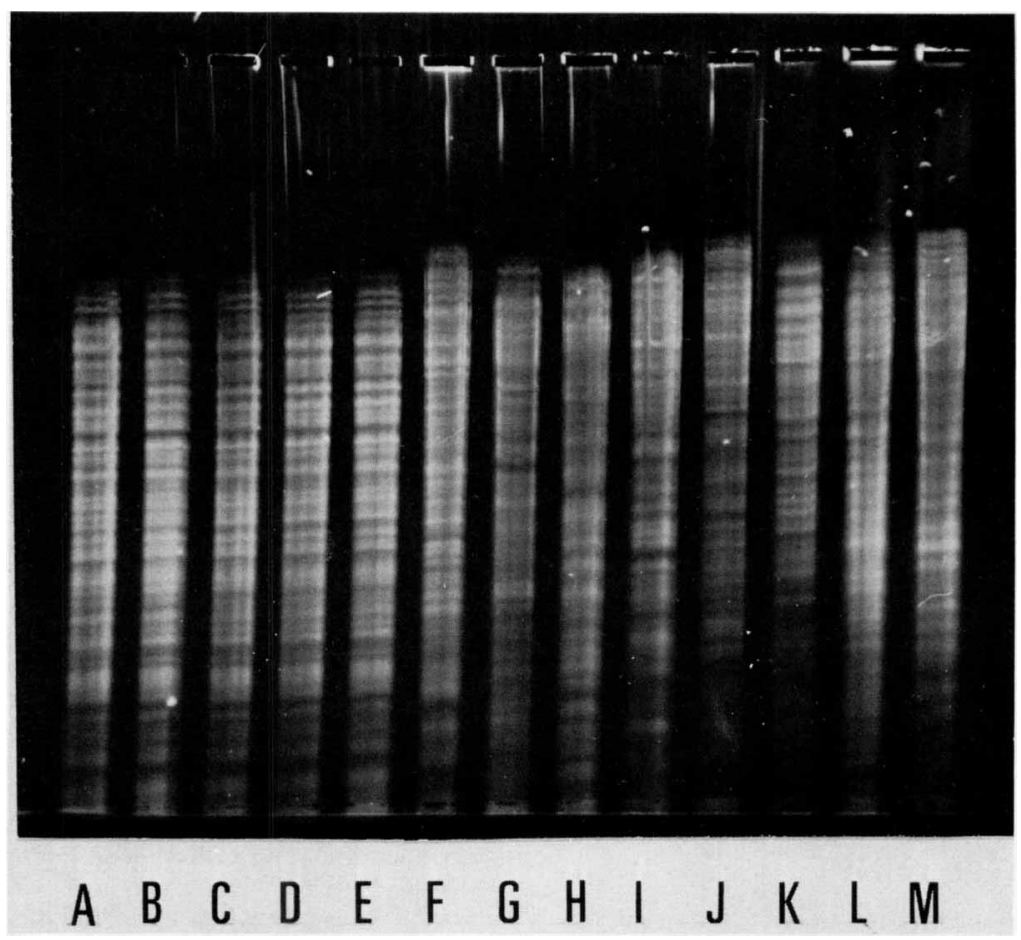

FIG. 1. Agarose gel electrophoresis of various DNAs digested with both EcoRI and EcoRV. Lane A, M. tuberculosis TMC 102 ${ }^{\mathrm{T}}$; lane B, $M$. bovis ATCC $19210^{\mathrm{T}}$; lane C. $M$. bovis BCG TMC 1011; lane D. $M$. microti TMC 1608; lane E, $M$. africanum TMC $5122 ;$ lane F, $M$. nonchromogenicum TMC $1481^{\mathrm{T}}$; lane G, $M$. intracellulare TMC $1406^{\mathrm{T}}$; lane H. M. kansasii TMC 1204 ${ }^{\mathrm{T}}$; lane I, $M$. avium TMC 706; lane J, M. scrofulaceum TMC $1323^{\mathrm{T}}$; lane K. M. haemophilum TMC $804^{\mathrm{T}}$; lane L, M. marinum TMC $1218^{\mathrm{T}}$; lane $\mathrm{M}, M$. asiaticum TMC $803^{\mathrm{T}}$.

demonstrated 95 to $100 \%$ relatedness with representative strains of $M$. tuberculosis and $M$. bovis. Two strains of $M$. microti also showed 90 to $100 \%$ relatedness with most strains of $M$. tuberculosis, $M$. bovis, and $M$. africanum. However, these strains of $M$. microti contained DNAs with slightly lower levels of relatedness $(85$ to $89 \%)$ to some strains of $M$. bovis and $M$. bovis BCG. $M$. africanum showed slightly closer relatedness with $M$. tuberculosis than with other members of the $M$. tuberculosis complex, although only one strain of $M$. africanum was examined in this study.

Restriction enzyme cleavage analysis showed that the distribution patterns of DNA fragments produced with a single enzyme (either $E c o$ RI, $E c o$ RV, $B g / \mathrm{II}, B c / \mathrm{I}$, or $K p n \mathrm{I}$ ) were indistinguishable among representative strains of the M. tuberculosis complex (data not shown). When DNAs of the strains of the $M$. tuberculosis complex were digested with two enzymes, such as EcoRI and EcoRV, which recognize totally different sequences, the patterns of restricted fragments were visually identical (Fig. 1).

In contrast, restricted fragments of DNAs derived from $M$. nonchromogenicum, $M$. intracellulare, $M$. kansasii, $M$. avium, $M$. scrofulaceum, $M$. haemophilum, M. marinum, and $M$. asiaticum by digestion with EcoRI and EcoRV showed various patterns, which differed significantly not only from those of the $M$. tuberculosis complex but also from each other (Fig. 1).

\section{DISCUSSION}

A total of 25 strains of the $M$. tuberculosis complex (consisting of $M$. tuberculosis, $M$. bovis, $M$. bovis BCG, $M$. microti, and $M$. africanum) contained chromosomal DNAs with almost identical basic properties, such as base ratio and genome molecular weight. A spectrophotometric assay of DNA-DNA hybridization showed more than $90 \%$ DNA relatedness among these strains, except for slightly lower levels of relatedness between $M$. microti and some strains of $M$. bovis and $M$. bovis BCG.

The extent of DNA relatedness estimated by using $\mathrm{C}_{0} \mathrm{t}_{0.5}$ values represents the degree of the stability of both stacking and pairing of bases within hybrid molecules (12). However, unmatched regions due to a deletion, insertion, or substitution of several nucleotides cannot be detected by the spectrophotometric assay employed in this study. Therefore, $100 \%$ relatedness does not necessarily mean identical sequences in the total stretch of chromosomal DNAs in two test samples.

In addition to the extremely high levels of DNA relatedness among strains of the $M$. tuberculosis complex as observed by the spectrophotometric assay, the distribution patterns of restriction fragments produced with several endonucleases, individually and in combination, were indistinguishable among selected strains of the complex, indicating almost identical distribution of specific sequences throughout the chromosomes.

The principle of restriction enzyme cleavage analysis is based on the fact that the frequencies and locations of specific DNA sequences in chromosomal DNA are characteristic of individual bacterial strains (11). Therefore, the same distribution pattern of restricted fragments observed among members of the $M$. tuberculosis complex implies that these DNAs are most likely the same. However, alterations in nucleotide sequences between two restriction sites cannot be detected by this method. These undetectable changes in DNA sequences may result in differentiation of five species of the $M$. tuberculosis complex, as reflected by their stable 
phenotypic differences. Among various strains of $M$. bovis $\mathrm{BCG}$, the diversity in virulence to animals $(5,10,13,20)$, antigenicity $(16,22,24)$, and bacteriological (13) and chemical (23) characteristics can also be explained in terms of undetectable minor alterations in chromosomal sequences which are, as a whole, almost identical among the 13 strains tested in this study.

In contrast to the extremely high levels of DNA relatedness among members of the $M$. tuberculosis complex, the DNAs of other slowly growing mycobacteria, including $M$. avium, $M$. kansasii, Mycobacterium gordonae, and $M$. intracellulare, are reportedly heterologous to the DNA of $M$. tuberculosis $(2,14)$. In addition to these species, significantly lower levels of DNA relatedness between $M$. tuberculosis and $M$. nonchromogenicum, $M$. scrofulaceum, $M$. marinum, $M$. haemophilum, or $M$. asiaticum were found by using spectrophotometric DNA hybridization and restriction endonuclease cleavage analyses in this study.

In conclusion, the experiments described above indicate the close evolutionary relationships among $M$. tuberculosis, $M$. bovis, $M$. bovis BCG, $M$. microti, and $M$. africanum, as evidenced by almost identical genomic DNAs. My data also support the reclassification of these species as a single species, as suggested by numerical taxonomy $(25,26)$.

\section{ACKNOWLEDGMENTS}

I am greatly indebted to $\mathrm{M}$. Tsukamura for discussion of numerical taxonomic data and to E. Goldman and M. Harter for interpretation of experimental data.

This investigation was supported by the World Health Organization, the Stony Wold-Herbert Fund, and the Heiser Program for Research in Leprosy.

\section{LITERATURE CITED}

1. Athwal, R. S., S. S. Deo, and T. Imaeda. 1984. Deoxyribonucleic acid relatedness among Mycobacterium leprae, Mycobacterium lepraemurium, and selected bacteria by dot blot and spectrophotometric deoxyribonucleic acid hybridization assays. Int. J. Syst. Bacteriol. 34:371-375.

2. Baess, I. 1972. Deoxyribonucleic acid relatedness among species of slowly-growing mycobacteria. Acta Pathol. Microbiol. Scand. Sect. B 87:221-226.

3. Bradley, S. G. 1973. Relationships among mycobacteria and nocardiae based upon deoxyribonucleic acid reassociation. J. Bacteriol. 113:645-651.

4. Brenner, D. J. 1983. Impact of modern taxonomy on clinical microbiology. ASM News 49:58-63.

5. Bunch-Christensen, K., A. Ladefoged, and J. Guld. 1968. The virulence of some strains of BCG for golden hamsters. Bull. W. H. O. 39:821-828.

6. Buraczewska, M., W. Manowska, and H. Rdultowska. 1971. Quick method for differentiating between virulent bovine and attenuated BCG bacilli. Am. Rev. Respir. Dis. 103:116-117.

7. Calmette, H., and C. Guerin. 1908. Sur quelques proprietes du bacille tuberculeux cultive sur la bile. C. R. Acad. Sci. 147: 1456-1459.

8. Coates, A. R. M., J. Hewitt, B. W. Allen, J. Ivanyi, and D. A. Mitchison. 1981. Antigenic diversity of Mycobacterium tuberculosis and Mycobacterium bovis detected by means of mono- clonal antibodies. Lancet ii:167-169.

9. David, H. L., M. T. Jahan, A. Jumin, J. Grandry, and E. H. Lehman. 1978. Numerical taxonomy analysis of Mycobacterium africanum. Int. J. Syst. Bacteriol. 28:467-472.

10. Dubos, R. J., C. H. Perce, and W. B. Schaefer. 1956. Differential characteristics in vitro and in vivo of several substrains of BCG. I-IV. Am. Rev. Tuberc. 74:655-715.

11. Ewens, W. J., R. S. Spielman, and H. Harris. 1981. Estimation of genetic variation at the DNA level from restriction endonuclease data. Proc. Natl. Acad. Sci. U.S.A. 78:3748-3750.

12. Freifelder, D. 1982. Physical biochemistry. Freeman and Co., San Francisco.

13. Gheorghiu, M., and P. H. Lagrange. 1983. Viability, heat stability and immunogenicity of four BCG vaccines prepared from four different BCG strains. Ann. Immunol. (Inst. Pasteur) 134C:125-147.

14. Gross, W. M., and L. G. Wayne. 1970. Nucleic acid homology in the genus Mycobacterium. J. Bacteriol. 104:630-634.

15. Harboe, M. 1981. Antigens of PPD, old tuberculin, and autoclaved Mycobacterium bovis BCG studied by cross immunoelectrophoresis. Am. Rev. Respir. Dis, 124:80-87.

16. Harboe, M., R. N. Mshana, O. Closs, G. Kronvall, and N. H. Axelsen. 1979. Cross-reactions between mycobacteria. II. Crossed immunoelectrophoretic analysis of soluble antigens of BCG and comparison with other mycobacteria. Scand. J. Immunol. 9:115-124.

17. Imaeda, T., L. Barksdale, and W. F. Kirchheimer. 1982. Deoxyribonucleic acid of Mycobacterium lepraemurium: its genome size, base ratio, and homology with those of other mycobacteria. Int. J. Syst. Bacteriol, 32:456-458.

18. International Working Group on Mycobacterial Taxonomy. 1980. Mycobacterial culture collection. Publication 80-289. National Institutes of Health, Bethesda, Md.

19. Jensen, K. A., I. Klaer, and L. Lundberg. 1968. Studies on the antigenic structure of mycobacteria. Acta Pathol. Microbiol. Scand. 73:450-458.

20. Jesperson, A., and M. W. Bentzon. 1964. The virulence of various strains of BCG determined on the golden hamster. Acta Tuberc. Scand. 44:222-249.

21. Karlson, A. G., and E. F. Lessel. 1970. Mycobacterium bovis nom. nov. Int. J. Syst. Bacteriol. 20:273-282.

22. Lind, A. 1959. Serological studies of mycobacteria by means of the diffusion-in-gel technique. Int. Arch. Allergy 14:264-280.

23. Minnikin, D. E., S. M. Minnikin, G. Dobson, M. Goodfellow, F. Portaels, L. Van Den Breen, and D. Sesardic. 1983. Mycolic acid patterns of four vaccine strains of Mycobacterium bovis BCG. J. Gen. Microbiol. 129:889-891.

24. Miura, K., S. Nagai, M. Kinomoto, S. Haga, and T. Tokunaga. 1983. Comparative studies with various strains of Mycobacterium bovis BCG on the production of an antigenic protein, MPB 70. Infect. Immun. 39:540-545.

25. Tsukamura, M. 1983 . Numerical classification of 280 strains of slowly growing mycobacteria. Microbiol. Immunol. 27:315-334.

26. Wayne, L. G. 1982. Microbiology of tubercle bacilli. Am. Rev. Respir. Dis. 125(Suppl.):31-41.

27. Wieten, G., J. Haverkamp, H. L. C. Meuzelaar, H. W. B. Engel, and L. G. Berwald. 1981. Pyrolysis mass spectrometry: a new method to differentiate between the mycobacteria of the "tuberculosis complex" and other mycobacteria. J. Gen. Microbiol. 122:109-118.

28. Yates, M. D., C. H. Collins, and J. M. Grange. 1978. Differentiation of BCG from other variants of Mycobacterium tuberculosis isolated from clinical material. Tubercle 59:143-146. 